\title{
PRUEBA PERICIAL Y CONOCIMIENTO PRIVADO DEL JUEZ: ENTRE EL OPTIMISMO Y LA DEFERENCIA
}

\author{
EXPERT EVIDENCE AND PRIVATE KNOWLEDGE OF THE \\ JUDGE: BETWEEN OPTIMISM AND DEFERENCE
}

IGNACIO M. SOBA BRACESCO*

\section{Resumen}

Hacer frente a la prueba pericial en el proceso jurisdiccional no fue, ni es, algo sencillo. Sin embargo, hoy en día, a los sujetos del proceso les resulta más simple acceder, por su cuenta, a conocimiento o información relativa a temas extrajurídicos que podrían ser de interés para el proceso. Qué hacer, entonces, con ese conocimiento privado (que puede, por ejemplo, obtenerse a través de internet) es una de las interrogantes que se plantean en el presente artículo. La capacitación adecuada será clave para no dejarse sorprender y para comprender las particularidades y las limitaciones de esa información o conocimiento extrajurídico, así como para lograr un mejor aprovechamiento de la prueba pericial.

\section{Palabras Clave}

Prueba pericial, conocimiento privado, internet, hecho notorio.

Artículo recibido para su evaluación el 17 de mayo de 2021, y aprobado para su publicación el 20 de julio de 2021.

" Profesor Adjunto y Profesor Adscripto de Derecho procesal en la Facultad de Derecho de la Universidad de la República Oriental del Uruguay. Presidente del Foro Uruguayo de Derecho Probatorio. Montevideo, Uruguay. Email: ignacio.soba@fder.edu.uy. 


\begin{abstract}
Facing the expert evidence in the judicial process was not, and is not, something simple. However, nowadays, it is easier for people (lawyers, judges) to access, on their own, knowledge or information regarding extra-legal issues that could be of interest to the process. What to do, then, with that private knowledge (which can, for example, be obtained through the internet) is one of the questions that are analyzed in this paper. Adequate training will be key to not being surprised and understanding the particularities and limitations of that information or extra-legal knowledge, as well as to make better use of the expert evidence.
\end{abstract}

\title{
Keywords
}

Expert evidence, private knowledge, internet, notorious facts / judicial notice.

\author{
«Algo llega siempre del mundo al proceso; \\ algo trae consigo (...) ese juez» \\ (cfr., CARNELLI, Lorenzo: El hecho notorio. \\ Olejnik, Santiago, 1943/2020, p. 91).
}

\section{INTRODUCCIÓN.}

Hay un brocardo que recuerda: iudex peritus peritorum (el juez es perito de peritos) ${ }^{1}$. Ello ha sido recogido -y relativizado- en muchos fallos jurisprudenciales, y también analizado por la dogmática procesalista y varias obras que estudian más concretamente la prueba científica y/o la prueba pericial ${ }^{2}$.

1 Algunos lo sustituyen, hoy en día, por el de iudex est custus peritorum. Lo que tiene algo de interés pues nos recuerda el rol de vigilante que debe tener el juez respecto de la prueba pericial. Utilizando expresiones que se asociaban o asocian a la culpa, se podría decir que los partícipes del proceso deben actuar diligentemente in eligendo (eligiendo los expertos adecuados, seleccionando los peritos idóneos, especialistas en el objeto de la pericia), así como in vigilando (cumpliendo un rol de gatekeeper en cuanto a la admisibilidad o, eventualmente, al valorar la prueba pericial).

2 En ese sentido, escojo como referencia ilustrativa (arbitrariamente, pues como dije es bastante amplia la bibliografía) alguno de los siguientes análisis: GASCÓN ABELLÁN, Marina: "Prevención y educación: el campo hacia una mejor ciencia forense en el 
El problema se puede plantear a través de algunas interrogantes. Por ejemplo, ¿pueden los jueces leer y utilizar la información obtenida del prospecto de un medicamento en internet o literatura especializada acerca de la psicología del testimonio?

Algo similar cabe preguntarse acerca de lo que sucede si un abogado cuestiona una pericia diligenciada a raíz del ofrecimiento de la contraparte, pero lo hace en base a cierta literatura científico-técnica que ha tenido oportunidad de consultar. En ese escenario, ¿los jueces se pueden apartar de una pericia en base a la información extrajurídica que aporta el abogado de una de las partes?

En ocasiones, las partes no pueden acceder a determinados expertos o no está a su alcance costear ciertas pericias, y entonces los abogados, o defensores, hacen considerables esfuerzos para contrarrestar la idoneidad, la metodología empleada por los expertos que ya han intervenido en el proceso.

Otra cuestión también compleja es aquella que se plantea en los casos en que cierta metodología ha sido empleada por el perito "A", siendo cuestionada con éxito por la parte que no había ofrecido dicha prueba (a partir del diligenciamiento de una «metapericia» efectuada por el experto "B"). Luego, en otro caso concreto tramitado ante el mismo juez "X", que había entendido en el proceso anterior, la parte no cuestiona esa metodología (quizás por no poder acceder o no poder costear los honorarios del perito "A", que le hubiera sido muy útil). Entonces, ¿qué puede hacer el juez " $\mathrm{X}$ " en ese segundo caso? ¿Se puede valer del conocimiento que obtuvo de "A" en el proceso similar previo?

En definitiva, las reflexiones que realizaré a continuación tienen lugar en escenarios en los que, de alguna manera, hay un déficit o ausencia de

sistema de justicia”. En: FERRER BELTRÁN, Jordi y VÁZQUEZ, Carmen (eds.): El razonamiento probatorio en el proceso judicial. Un encuentro entre diferentes tradiciones. Marcial Pons, Madrid, 2020. pp. 239-267; NIEVA FENOLL, Jordi: La valoración de la prueba. Marcial Pons, Madrid, 2010. pp. 285 ss.; PICÓ I JUNOY, Joan (Director), ANDINO LÓPEZ, Juan y CERRATO GURI, Elisabet (Coordinadores): La prueba pericial a examen. Propuestas de lege ferenda. Bosch, Barcelona, 2020; PICÓ I JUNOY, Joan (Director) y DE MIRANDA VÁZQUEZ, Carlos (Coordinador): Peritaje y prueba judicial. Bosch, Barcelona, 2017; SOBA BRACESCO, Ignacio M.: Estudios sobre la prueba testimonial y pericial. La Ley Uruguay, Montevideo, 2020; VÁZQUEZ, Carmen: De la prueba cientifica a la prueba pericial. Marcial Pons, Madrid, 2015 (en donde la autora refiere al tema de la valoración, situándolo entre la deferencia y la educación, pp. 80-82, esta expresión que Vázquez toma de Allen y Miller, me sirve ahora de inspiración para la elección del título). 
conocimiento experto, lo que genera un terreno fértil para potenciar la creatividad de los sujetos del proceso.

\section{LOS VAIVENES DE LA JURISPRUDENCIA.}

Acudiré a algunos fallos de interés a nivel comparado para evidenciar la problemática y obtener insumos que permitan acercarnos un poco más a la misma.

En Italia, la Corte Suprema de Casación (Sección Penal III), en una sentencia de 14 de abril de 2020 ( ${ }^{\circ}$ 12026), anuló una sentencia vinculada a un delito de violencia sexual (reenvía el expediente a otro Tribunal y mantiene la condena por un delito de maltrato familiar o violencia doméstica), señalando que el juez no puede, para rebatir lo afirmado por un perito o consultor de parte, apoyarse en su conocimiento privado, encontrando elementos de juicio por su propia iniciativa y evaluándolos sobre la base de su criterio o juicio personal.

El consulente di parte (testigo experto, consultor o perito de parte) ofrecido por la defensa había señalado que no se podía determinar en el caso la existencia de un estado de inconsciencia tan profunda de la mujer como para permitir la perpetración de la violencia sexual.

Por su parte, el juez -en el pronunciamiento revisado en casaciónafirmó que los medicamentos tomados por la víctima de la supuesta agresión sexual tenían efectos hipnóticos y sedantes (generan un estado de sueño profundo, que le permitió al imputado perpetrar la agresión sexual aprovechado la semi inconsciencia de la víctima). Se habría llegado a esa conclusión, contraria a la del perito de parte, luego de obtener información a través de la lectura del prospecto del medicamento en Internet.

La Corte italiana señaló que el tribunal de mérito no solo no demostró saber la dosis con la que los medicamentos en cuestión fueron tomados, lo cual es fundamental para evaluar los efectos que tales medicamentos pueden causar, sino que también dedujo la sustancia de estos efectos, con una valoración completamente autorreferencial, basado en la simple lectura realizada por el juez de primera instancia del prospecto, de forma privada en Internet, que acompaña a los paquetes individuales con los que los medicamentos en cuestión se comercializan. Añadió que se trataba de información genérica, no específica para el caso concreto -no se consideran cantidades ingeridas en el caso, por ejemplo-, que no ingresa al proceso a través de una pericia (o nueva pericia). 
En definitiva, la Corte italiana manifestó que no se puede ni debe acudir a la ciencia o conocimiento privado del juez (en el caso, aquello que fue obtenido a través de Internet), para sustituir la realización de una pericia (o nueva pericia) $)^{3}$.

En Colombia ${ }^{4}$, en tanto, la Corte Suprema de Justicia (sala de casación civil), SC13925-2016, Radicación n ${ }^{\circ}$ 05001-31-03-003-2005-00174-01, del 30 de septiembre de 2016 (ponente Ariel Salazar Ramírez), realizó abundantes citas médicas directamente en la sentencia, transcribiendo literatura médica (la cual aparentemente no formó parte de ninguna pericia), concluyendo que:

"La literatura médica al respecto, como ha quedado en evidencia, es clara, copiosa y uniforme, estando al alcance de cualquier persona de mediana capacidad intelectiva que se proponga consultarla y, con mayor razón, de los profesionales de la medicina.

En los aludidos protocolos se indica que no se debe recetar nada vía oral y nunca prescribir analgésicos hasta tener un diagnóstico comprobado o definitivo de manejo, pues éstos, al calmar el dolor, enmascaran los síntomas de la enfermedad. (Protocolos de urgencias, Abdomen Agudo. Programa de las Naciones Unidas para el desarrollo de Antioquia, Medellín, 1992. p. 75, 76)."

Más adelante se señala que no solo se tuvo en cuenta lo informado por el perito (que lo hubo), sino un cúmulo de insumos. A saber:

"A partir de la valoración de los protocolos y guías médicas, las declaraciones, la historia clínica y las respuestas del perito, se concluye que la atención brindada a la señora Luz Deisy Román el 29 de mayo de 2002 fue extremadamente negligente, pues la médica que la atendió no le mandó los exámenes físicos, de laboratorio, radiológicos ni de tomografía que en esa época estaban prescritos para la identificación de la causa de la dolencia que la aquejaba".

Luego, en el capítulo referido a la «intervención quirúrgica» también se refiere a literatura médica, señalándose que la misma es enfática en advertir determinadas cuestiones concretas que allí se refieren. La

3 De la sentencia no he podido extraer que se hubiese diligenciado previamente una pericia de designación judicial. Es más, la sentencia comentada va en la línea de exigir el diligenciamiento de prueba pericial en virtud del tipo de enunciado fáctico y de las habilidades científico-técnicas específicas requeridas para su adecuada comprensión.

4 Agradezco al Prof. Maximiliano Aramburo, de Colombia, por haberme facilitado las sentencias de su país. 
sentencia está plagada de consideraciones acerca de la literatura médica que se consultó (desconozco en base a qué criterio), de la cual se extraen ciertas conclusiones.

Posteriormente, en otro caso, la misma Corte Suprema de Justicia (sala de casación civil, Luis Armando Tolosa Villabona, magistrado ponente), SC5186-2020, radicación 47001-31-03-004-2016-00204-01, de 18 de diciembre de 2020, indicó que no casaría una sentencia impugnada que había llegado a su conocimiento, pero efectuó varias consideraciones que ahora resultan de interés.

Allí se señala que el Tribunal inferior había llegado a la conclusión de que no había existido un tratamiento indebido (contrariando lo señalado por peritos), en base a información obtenida de sitios web, que indicaban que el diagnóstico y el tratamiento se correspondían con los síntomas de la paciente al momento de requerir atención sanitaria. Dejó sentadas las diferencias entre el perito, la testigo técnica y la literatura médica (en ese caso, sobre la naturaleza de la desametaxona suministrada). Aquí un extracto de la sentencia:

"En sentir del ad-quem, la experticia y el testimonio técnico eran insuficientes para acreditar "el error en el diagnóstico y tratamiento". El hecho tampoco podía dejarse demostrado con la falta de contestación de la demanda. En materia de responsabilidad médica, las reclamaciones requieren ser demostradas por quienes las plantean."

Los recurrentes critican, concretamente, que el Tribunal acudió a la información web, «ausente en el proceso.

En sus considerandos la Corte recoge la preocupación de los recurrentes por la incorporación indebida y acrítica de conocimiento obtenido a través de internet, y manifiesta:

"No es válido realizar en la sentencia disquisiciones teóricas desde esa literatura, mutándola en soporte fáctico y jurídico con presunto criterio de certeza; ni tenerla como medio probatorio adicional y al margen de la prueba allegada a la foliatura en los términos de la ley de enjuiciamiento correspondiente.

Por una parte, el "conocimiento científico afianzado" llega al proceso, muchas veces, sin haber surtido el trámite de contradicción (...)"

"Es inalcanzable la cantidad de información que se produce a diario, por ejemplo, en medicina. Las más de 20.000 publicaciones biomédicas periódicas y el catálogo de no menos de 250.000 artículos anuales, tan 
sólo en la Biblioteca de Medicina de los Estados Unidos (Venturelli, 1997), demuestra la imposibilidad absoluta de abarcarlo o trasmitirlo todo. El crecimiento exponencial del conocimiento y de la literatura disponible induce a profesores, como el Dr. Sydney Burwell, quien fuera Decano de la Escuela de Medicina de la Universidad de Harvard, a advertir: “(...) en 10 años estará probado que la mitad de lo que usted ha aprendido como estudiante de medicina es equivocado, y el problema es que ninguno de sus profesores sabe qué mitad será" (Sackett, Straus, Richardson, Rosenberg Haynes, 2002). Hoy se dice que el saber médico se renueva cada 5 arios hasta el 75\%30. El ejemplo inmediato, son estos tiempos de pandemia(...)"

"El Tribunal, en una afrenta a las reglas de contradicción y defensa, realizó juicios de valor respecto de elementos no incorporados debidamente al litigio."

Ahora bien, por qué razón entonces la Corte Suprema de Justicia colombiana rechaza la casación (y con ello, en definitiva, se desestima el reclamo por responsabilidad médica). Pues bien, la Corte valora la pericia, así como el testimonio técnico (una médica cuya idoneidad se cuestiona por no ser experta en oftalmología, que era la especialidad requerida), señalando:

"Contrastado lo que precede, surge de bulto que el dictamen pericial y los conceptos dados por la doctora Yolanda Sánchez, no son fiables. Carecen de fundamentación. De ahí que no superan los criterios racionales de aceptabilidad suficiente, adecuación consistencia interna.

En efecto, se trata de conclusiones meramente subjetivas. No vienen precedidas de una explicación acerca de la existencia de un método o técnica aceptada por la ciencia médica que avale un examen en lugar del otro, según los síntomas informados o detectados en la paciente. Por esto, no es posible evaluar su aplicación a los hechos del caso. (énfasis agregado)."

La Corte colombiana cuestiona la fundamentación del perito (por inexistente), ya que sólo se limita a expresar que se debió solicitar un examen " $X$ " pero no da explicaciones sobre el sustento de su afirmación.

Finalmente, consideremos el caso de algunas sentencias uruguayas. La Suprema Corte de Justicia, en sentencia $n^{\circ}$ 273/2013, de 10 de junio de 2013 (Chediak -redactor-, Chalar -discorde, Larrieux, Pérez Manrique, Ruibal), se apartó de un informe médico ginecológico (elaborado en una 
instancia administrativa previa a requerimiento del Ministerio de Salud Pública $^{5}$ ) poniendo de relieve la brevedad del informe del experto.

En ese caso -según se dice en la sentencia- el propio experto reconoció lo voluminoso del expediente que tuvo a estudio, pese lo cual pudo sintetizar sus particularidades y sus conclusiones en tan solo, prácticamente, una carilla.

Asimismo, la Corte uruguaya hizo hincapié en que las conclusiones a las que arribó el experto «no fueron adecuadamente fundadas ni se apoyaron en bibliografía especializada, o, al menos, eso no fue explicitado por el profesional:

"Por mencionar solo una crítica que se le puede realizar al informe, repárese en que cuando dice que "la atención se mantuvo en todo momento dentro de los cánones aceptados para el control de un trabajo de parto", no explica cuáles son esos parámetros aceptados, así como tampoco desarrolló su lacónica expresión de que "no existen elementos que puedan hablar de irregularidades en la atención de la referida abonada ni durante su trabajo de parto ni en el período expulsivo del mismo" (...)

"Finalmente, puede decirse que se trataron de conclusiones que no provinieron de una junta médica (...), sino de un solo médico que no fundamentó -aunque fuera mínimamente- su informe y que formuló aseveraciones que, como se verá en el Considerando próximo, resultaron contradichas por la bibliografía médica especializada que aportó al proceso la propia parte demandada; motivos que conducen a sostener, sin hesitación, que el valor científico que se le puede reconocer es nulo. (énfasis agregado)."

Tal como se puede apreciar, se destacan básicamente dos cosas: una, a mi criterio la determinante, que es la falta de fundamento del informe; otra, la importancia de la bibliografía médica especializada aportada por la parte demandada.

Sin perjuicio de ello, vale aclarar que se terminó condenando, en función de la existencia de otro peritaje (de un médico de otra especialidad diferente a la del otro perito neuropediatra).

$5 \quad$ El tema no es menor. En la discordia a ese fallo, el Ministro Chalar expresa que se debió diligenciar prueba pericial ginecológica en el propio expediente judicial (para avalar la condena). 
Es más, señala la Suprema Corte de Justicia de Uruguay, que la propia bibliografía especializada que agregó la demandada avala las conclusiones de esa pericia.

Nuevamente aquí el problema está en cómo determinar que esa bibliografía especializada -sea que la proporcione una de las partes, sea que se obtenga de una biblioteca tradicional o de fuentes internet por parte del juez (lo que podría agravar el problema por la falta de contradictorio)- es la pertinente (o fit, ajustada a los hechos del caso), se encuentra actualizada, ha sido sometida a algún tipo de control como la revisión por pares (sin perjuicio de las críticas que ha merecido el sistema de peer review), no existe otra bibliografía que sostenga lo contrario, etc ${ }^{6}$.

La cuestión fundamental parece radicar en valorar críticamente las falencias del dictamen experto (en lo metodológico y en el aspecto de fondo), sin incurrir en los males de la deferencia absoluta (esa que puede transformar al experto en el «amo oculto» del juez) ${ }^{7}$. Pero, igualmente, reconozco que abundan las zonas grises y que resulta difícil determinar en qué consiste esa valoración crítica, no deferente, cuando se tiene por delante aspectos que hacen, reitero, a la metodología o al contenido del informe o exposición del experto.

$6 \quad$ El juez actual se inserta en un contexto diferente al del juez del siglo diecinueve o incluso del siglo veinte; pasamos del conocimiento privado tradicional (STEIN, Friedrich: $E l$ conocimiento privado del juez, segunda edición, traducción y notas DE LA OLIVA SANTOS, Andrés. Temis, Bogotá, 1893/1999); al uso de información obtenida de internet por parte de los jueces, a la facilidad y al exceso de insumos (muchos de dudosa confiabilidad). Precisamente, ahí radica un problema de las personas (al cual no escapan los jueces): el poder distinguir, separar la información confiable de aquella que no lo es (paso previo al analizar o valorar la información). No digo que sea un problema novedoso, digo que se ha potenciado enormemente.

7 «...los jueces, a menudo, son incapaces de entender sus misteriosos informes [de los peritos, refiriendo al derecho continental]. Se está extendiendo el miedo de que encubiertamente los tribunales estén delegando su poder de decisión a un extraño sin legitimidad política. ¿Se está convirtiendo el servidor aparente del juez en su amo oculto? A pesar de los heroicos esfuerzos de reconciliación teórica del jurista, la dependencia respecto de los impenetrables conocimientos científicos aumenta las tensiones con la libertad del juez para valorar las pruebas de acuerdo con su sana crítica. Una de las piedras angulares del moderno derecho probatorio continental -el principio de la libre valoración de la prueba- requerirá en un futuro próximo repensarse y reconceptualizarse». Cfr., DAMASKA, Mirjan R.: El derecho probatorio a la deriva, traducción de PICÓ I JUNOY, Joan. Marcial Pons, Madrid, 2015. p. 151. 
A modo de ejemplo, en sentencia $n^{\circ} 4 / 2021$, de 11 de febrero de 2021, el Tribunal de Apelaciones en lo Penal de $1^{\circ}$ Turno (Gatti -redactora-, Torres, Reyes) expresó:

"el Perito informó que la técnica de entrevista clínica y forense es la metodología por excelencia empleada en estos casos, sin que la Defensa haya aportado información de calidad para destruir tal afirmación.

Ningún valor tienen para ello las afirmaciones efectuadas por la propia Defensa al formular sus agravios acerca de que técnicas debieron emplearse (...). Se trata de meras afirmaciones de la propia parte, sin sustento probatorio alguno.

En todo caso, si lo que pretendía era cuestionar las técnicas empleadas por el Perito, en su momento, debió haber solicitado prueba al respecto. Nada lo privaba de citar a otro Perito para ser interrogado sobre el punto. Pero no habiéndolo acreditado, mal puede pretenderse tener por justificados sus afirmaciones en cuanto a las técnicas "actuariales" o el modelo "AVD" que según sus dichos sería el empleado en Europa y Estados Unidos en la actualidad. Y en todo caso, más allá de lo que plantea respecto a este punto, nada de lo allí sostenido (...) invalida en concreto la conclusión de pericia. (énfasis agregado)".

Conforme se puede apreciar, en esta sentencia penal uruguaya, el Tribunal consideró fundado el peritaje (esto es, que el perito explicó la metodología).

Y ahí está uno de los puntos: decidir si se puede o no cuestionar cómo el perito fundamenta su dictamen. Entiendo que sí, que es labor jurisdiccional, y que para hacer eso no es necesario diligenciar otra prueba pericial (ahí podría existir un matiz con el Tribunal), pues de lo contrario se estaría admitiendo que no habría posibilidad de apartarse del dictamen de un perito sin otro perito que afirme lo contrario (sería necesario que la norma procesal, la ley, avalara una especie de capitis deminutio jurisdiccional de ese tenor).

Para ello pienso que el interrogatorio resulta una herramienta crucial (tanto de las partes como de los jueces). Por supuesto que interrogar un perito no es sencillo (un peritaje de signo contrario allanaría el camino), sin embargo, tampoco es una misión imposible o inverosímil. 


\section{ENTRE EL OPTIMISMO Y LA DEFERENCIA. LA CAPACITACIÓN COMO CLAVE EN LA OPTIMIZACIÓN DE LA PRUEBA PERICIAL.}

Conforme se ha indicado en el título, el tema planteado sirve para recordar la ya citada obra de Friedrich Stein sobre el conocimiento privado del juez, y para volver sobre el debate entre el juez optimista / omnisciente (el que, con un criterio optimista, cree poseer o poder adquirir los conocimientos que no tiene $)^{8}$, y el juez deferente, que considera, casi que como de sentido común, que los jueces estén a lo dictaminado por los peritos (acríticamente).

El camino intermedio (si me fuera permitido el acrónimo: el camino de la «optimencia» o el «defermismo»), considero, pasa por no prescindir de las pericias (o aportes de expertos) y fortalecer la capacitación de los sujetos del proceso (abogados, jueces), ya que estos -sea en los alegatos, sea en las sentencias o resoluciones- no sólo pueden, sino que tienen la carga o el deber de valorar las pericias junto con el resto de la prueba.

Para ello, hay que dotarlos de herramientas (conocimiento) que les permitan ejecutar interrogatorios más eficaces; que ayuden a discernir si resulta conveniente, o no, la impugnación de un peritaje (o, si fuese el juez o jueza, hacer lugar o no a esa impugnación); o si son necesarias, o no, nuevas o ulteriores pericias.

Sin desconocer que la decisión sobre el tipo de capacitación que hubiese que instrumentar es también un problema en sí mismo.

Insisto, la capacitación es relevante tanto en temas procesales (de regulación de la prueba pericial), como de epistemología jurídica o de razonamiento probatorio. La capacitación adecuada facilitará, por ejemplo, un mejor aprovechamiento del conocimiento extra jurídico; la comprensión de bibliografía ajena a lo jurídico que eventualmente se incorpore al proceso; o también, en ocasiones, de los libros o artículos jurídicos que incluyen la mención de problemas o cuestiones extrañas al derecho'.

$8 \quad$ Algo así como un sesgo o efecto Dunning-Kruger, que sostiene que las personas que carecen de competencia en ciertos asuntos, a menudo no están preparadas para reconocer esa incompetencia, pero trasladado a la prueba.

9 En esos casos, la interrogante es si pueden los litigantes o los jueces recurrir a estos materiales que refieren -para poner algunos ejemplos del ámbito probatorio- a la psicología del testimonio o psicología forense en estudios sobre la prueba testimonial o testifical, la declaración de víctimas o el reconocimiento de personas, o aquellos que aluden a temas de tecnología o informática en lo que son análisis acerca de documentos electrónicos, etc. ¿Tienen los juristas que escriben esos trabajos la capacitación para entender o contextualizar el conocimiento extra jurídico que emplean en sus obras?, 
Parece obvio decirlo, pero qué garantías se tienen respecto de ese conocimiento obtenido a través de internet, plasmado en libros que se han consultado en una biblioteca o en línea, así como en el caso, ya mencionado, de los propios libros o artículos jurídicos. En ese sentido, Schauer ${ }^{10}$ ha constatado que los jueces -y también los abogados- «... han venido citando y buscando apoyo en revistas no jurídicas -de economía, sociología, psicología y ciencias políticas, en libros sobre temas no jurídicos y en artículos de periódicos y revistas populares». Según he explicado, esto se puede tornar muy delicado, entre otros motivos, por la falta de control de fiabilidad de dichas fuentes de información, las que pueden generar en el juez la ilusión del conocimiento. Pero claro, nada de esto resulta novedoso, a poco que se consultan obras como la de José De Vicente y Caravantes, que en el año 1856 señalaba:

“...aun cuando el juez por sus estudios especiales se hallase con los conocimientos necesarios para poder formar un juicio acertado de aquellos hechos [hechos que versan sobre algún arte, oficio, ciencia o profesión], no podrá considerarse como perito para el efecto de dejar de nombrar los que la ley establece, y de oir su dictámen con arreglo á la misma, si bien aquella instruccion le servirá para guiarle en la apreciacion que forme del dictámen emitido por aquellos....".

Con la capacitación adecuada se puede transitar un camino que haga más fuerte, de mejor calidad, aquellas operaciones intelectuales de control de la admisibilidad de la prueba que se pretende introducir a partir del aporte de expertos, o la propia valoración judicial (tanto en aspectos formales-metodológicos como sustanciales).

Por todo esto entiendo que no solo es oportuno que las partes puedan interrogar a los peritos, sino también los jueces (incluso si no se admiten pruebas periciales de oficio, respecto de las pericias de las partes, entiendo cabe admitir preguntas para que los peritos den explicaciones) ${ }^{11}$.

¿se trata de referencias actualizadas al conocimiento extra jurídico?, ¿contemplan las diferentes posiciones o visiones que pueden llegar a existir en la o las comunidades científicas, técnicas, académicas?, etc. Como se puede apreciar, la disyuntiva que surge es similar a la que se presenta con las fuentes de información públicas, la bibliografía extra jurídica o el conocimiento privado obtenido a través de las propias capacitaciones.

10 SCHAUER, Frederick: Pensar como un abogado. Marcial Pons, Madrid, 2013. p. 98.

11 Cabe preguntarse: ¿qué actitud del juez permite encontrar la mejor explicación posible acerca de lo sucedido fácticamente o, en su caso, favorece o contribuye en mayor medida a la búsqueda de la verdad? Es la actitud activa del juez, no la pasiva, la que permite -obviamente respetando garantías básicas de todo proceso- el obtener la información 
Nieva Fenoll ${ }^{12}$ ha expresado que, si el juez posee los conocimientos técnicos, siendo imparcial, los aplicará de modo imparcial exactamente igual que realizará el resto de su labor. Sin embargo, destaca el citado profesor, lo más prudente sería realizar una pericia, que permita el control de las partes, y que el juez utilice sus conocimientos durante el interrogatorio del perito.

El interrogatorio, debidamente preparado, es clave. Con la preparación adecuada, el interrogatorio podría versar sobre los siguientes tópicos: las credenciales académicas, profesionales, de investigación del experto ${ }^{13}$; el eventual vínculo con las partes o con personas allegadas a estas; la pertenencia y demarcación de la comunidad científica, académica y/o institucional a la que directa o indirectamente se encuentre vinculado el experto; la bibliografía (el tipo de estudio cuantitativo o cualitativo en el que se basa, su actualidad, su revisión por pares, etc.), las «fuentes» públicas o privadas utilizadas para elaborar informes, así como el origen y la trazabilidad de otro tipo de insumos que se hubiesen utilizados; la metodología empleada en el caso concreto (si es que la hubo), si la ha empleado en otras pericias o informes con anterioridad, si la ha empleado en su ejercicio profesional, etc., indicando, en su caso, posibles márgenes de error; grado de aceptación de dicha metodología en la o las comunidades científicas o técnicas, etc. (pudiendo o no coincidir con la comunidad en la que se reconoce el propio perito) ${ }^{14}$.

necesaria para la adopción de la decisión judicial. En este polémico punto, se puede recordar que el cross examination es, para algunos, tan solo una utopía (cfr., VÁZQUEZ, Carmen: op. cit., pp. 175-176).

12 NIEVA FENOLL, Jordi, op. cit., p. 285.

13 Destaca Nieva Fenoll que, si bien es un aspecto en el cual se tiene que ingresar al momento de tomarle declaración al perito, es perfectamente posible que el perito no tenga un gran currículum (en especial, peritos noveles), pero que haya realizado un dictamen de calidad. Para corroborar estos extremos es importante el interrogatorio. Ibídem, pp. 308-309.

14 Se podría pensar en un interrogatorio enfocado en esos y otros puntos. El caso de la Corte Suprema de EE.UU., Daubert v. Merrell Dow Pharmaceuticals, Inc., 509 U.S. 579 (1993) ofrece algunas pautas, así como, por ejemplo, lo que surge del Derecho positivo (a modo ilustrativo, Federal Rules of Evidence, $\mathrm{N}^{\circ} 702$; el contenido mínimo del dictamen pericial que se plasma en el art. 226 del Código General del Proceso colombiano; o las referencias a la metodología y otros aspectos del informe en el art. 473 del Código de Procedimiento Civil brasileño). Según Taruffo, los criterios Daubert -tema sobre el que ya hay abundante doctrina en el derecho continental- refieren sucintamente a: la controlabilidad y falseabilidad de la teoría científica o la técnica en la que se fundamenta la prueba; el porcentaje de error conocido o potencial, así como el cumplimiento de los estándares correspondientes a la técnica empleada; la publicación en revistas sometidas al control de expertos, de la teoría o la técnica en cuestión; la existencia de un consenso 
Claramente, en caso de no poder recurrir a estos otros ámbitos del conocimiento que se incorporan al proceso a través de informes o declaraciones de expertos, el juez no podría fundamentar o motivar correctamente su decisión, pudiendo incluso caer en la arbitrariedad por la falta de una adecuada comprensión del fenómeno técnico-científico que forma parte del caso. Dicha especificidad y necesariedad de la prueba pericial conlleva, por su parte, su insustituibilidad (la necesidad de la prueba pericial suele establecerse por el propio legislador ${ }^{15}$ ). La necesidad de la prueba hace que el juez no sustituya al perito, al tiempo que el perito tampoco sustituye al juez.

En definitiva, al igual que los expertos pueden requerir de algún tipo de capacitación para integrarse y participar cómodamente del ámbito forense, de la litigación, del proceso (un espacio institucional que hasta

general de la comunidad científica interesada. Aunado a esto, el conocimiento en cuestión debe ser fit, es decir, directamente relevante y concretamente útil para decidir sobre los hechos del caso (cfr., TARUFFO, Michele: La prueba. Marcial Pons, Madrid, 2008. p. 283; así como, HAACK, Susan: Filosofia del derecho y de la prueba. Marcial Pons, Madrid, 2020, en especial, pp. 183-236, 329-333; VÁZQUEZ, Carmen: op. cit., pp. 91 ss., entre muchos otros). En el derecho continental estos criterios podrán ser útiles, no sólo para admitir o excluir los medios de prueba científica, sino también para la valoración. Por su parte, Nieva Fenoll también presenta su clasificación a los efectos de señalar aquello del dictamen que se debería controlar, siguiendo aquellas pautas: «1. Que las técnicas y teorías cientificas utilizadas para obtener datos y conclusiones han sido aplicadas previamente, son relevantes y están generalmente aceptadas por la comunidad cientifica internacional [para ello se deberán mencionar publicaciones de calidad o especializadas empleadas para realizar la pericia, que la técnica empleada por el perito es de uso regular, y de modo pormenorizado, el procedimiento o iter técnico que lo le permitió arribar a sus conclusiones] (...). 2. Que las técnicas utilizadas se han aplicado según los estándares y normas de calidad vigentes (...). 3. Que el dictamen contenga información sobre el posible grado o nivel de error y también el nivel o gradación de variabilidad e incertidumbre de los datos obtenidos por la citada técnica o teoría cientifica (...). 4. Que el dictamen se basa en suficientes hechos y datos (...)» (la cursiva pertenece al original). NIEVA FENOLL, Jordi: op. cit., pp. 295-299.

15 La necesidad de esta prueba aparece mencionada expresamente en los textos legales, o se deriva de las hipótesis de procedencia de la prueba pericial. A modo ilustrativo, véase en Argentina, el art. 457 del Código Procesal Civil y Comercial de la Nación, y art. 161 del Código Procesal Penal federal; en Brasil, el art. 156 del Código del Proceso Civil; en Chile, el art. 411 del Código de Procedimiento Civil y art. 314 del Código Procesal Penal; en Colombia, el art. 226 de su Código General del Proceso y art. 405 del Código de Procedimiento Penal; en España, el art. $335 n^{\circ} 1$ de la Ley de Enjuiciamiento Civil 1/2000; el art. 456 de la Ley de Enjuiciamiento Criminal (que además de referir a la necesidad, también alude a la conveniencia de contar con estos conocimientos extrajurídicos); en Uruguay, el art. 177 del Código General del Proceso y art. 178 del Código del Proceso Penal (que al igual que en el caso español, refiere a necesidad y conveniencia). 
les puede parecer ceremonial, con excesivo rigor formal sino están habituados al mismo); los abogados, abogadas, jueces y juezas, pueden y deben exigir mayor y más adecuada capacitación para elegir a las y los expertos adecuados, para dialogar o interrogarlos en el proceso (de un modo útil, pertinente, conducente, fundamentalmente en aspectos de sustento y fundamento metodológico de lo que están llamados a exponer en el proceso), valorar sus afirmaciones, así como para, eventualmente, impugnar o resolver las impugnaciones atinentes a sus conclusiones.

\section{REFLEXIÓN FINAL: EL JUEZ Y LAS COMPLEJIDADES DE LO NOTORIO.}

A modo de cierre, decir que fuera del proceso, acceder a información resulta cada vez más simple. Esto es notorio, pero a su vez, parecería que ya nada es notorio.

A tal punto podríamos considerar que casi todo ya es notorio, conocido o pasible de ser conocido por todos y todas, que, a partir de una búsqueda sin mucha diligencia a través de internet, bases de dato en línea, Wikipedia, algunas redes sociales o en ciertas aplicaciones móviles, podemos creer que accedemos al conocimiento de ilustrados enciclopedistas.

Sin embargo, un sinfín de aclaraciones y advertencias se imponen. La información abunda, puede ser hasta excesiva, pero ¿es realmente información? Lo que tiene apariencia de información, puede no ser, en puridad, fuente de conocimiento de calidad, fiable, atendible.

Con mucha más facilidad que antaño, se puede acceder a revistas supuestamente especializadas, a conferencias de quienes dicen ser los especialistas más encumbrados, pero también, a fake news (noticias falsas), información alterada, manipulada, posverdad (para aquellos que entienden que es posible de algún modo acceder o aproximarse a la verdad, también podría haber algo más allá de la verdad), lo deep fake, información proveniente de pseudociencias, y un largo etc. ${ }^{16}$.

16 Según el diccionario de la lengua española, de la Real Academia Española, posverdad viene de pos- y verdad, trad. del ingl. post-truth, y se la define lexicográficamente como la «Distorsión deliberada de una realidad, que manipula creencias y emociones con el fin de influir en la opinión pública y en actitudes sociales. Los demagogos son maestros de la posverdad». En palabras de Vattimo, invocando la realidad como un juego -a su criterio- de interpretaciones en conflicto: «Adiós a la verdad: así podríamos expresar, de manera más o menos paradójica, la situación de nuestra cultura actual, ya sea en sus aspectos teóricos y filosóficos ya sea en la experiencia común. En referencia a esta 
Podemos ser vulnerables digitales, víctimas, sujetos de una falsa sensación de seguridad, en el sentido de creer que estamos informados, cuando no lo estamos. Entonces, y si es que ello es posible, ¿cómo gobernamos nuestro contacto con la información? Nuevamente, una de las vías es a través de la capacitación adecuada a la que he aludido (sin perjuicio de lo que pueda resultar la incorporación de herramientas de inteligencia artificial al proceso).

La esencia del (debido) proceso jurisdiccional impide que se lo considere como una herramienta opaca y acrítica.

El proceso jurisdiccional, en el que convergen distintos sujetos, es y será un entramado institucional de controles, de contradicción y de garantías, tanto para el debate jurídico como para el debate fáctico, el razonamiento probatorio en general, y la incorporación de conocimiento extrajurídico, en particular. Ello hace que lo que suceda en el proceso tienda a no ser un acto de fe, sino un espacio para la adopción de decisiones que se aspira que sean racionales. A veces puede ser que parezca un instrumental algo pesado (por supuesto, desearía que fuera más simple), incluso en ocasiones hasta anticuado, pero las garantías que lo constituyen no podrán nunca pasar de moda, salvo para ser mejoradas. Lo mismo respecto de los debates acerca de la prueba pericial. Repensemos su regulación cuando nos parezca deficitaria, a la luz de todos estos nuevos desafíos.

\section{BIBLIOGRAFÍA.}

CARNELLI, Lorenzo: El hecho notorio. Olejnik, Santiago, 1943/2020.

DAMASKA, Mirjan R.: El derecho probatorio a la deriva, traducción de PICÓ I JUNOY, Joan. Marcial Pons, Madrid, 2015.

GASCÓN ABELLÁN, Marina: "Prevención y educación: el campo hacia una mejor ciencia forense en el sistema de justicia". En: FERRER BELTRÁN, Jordi y VÁZQUEZ, Carmen (eds.): El razonamiento probatorio en el proceso judicial. Un encuentro entre diferentes tradiciones. Marcial Pons, Madrid, 2020.

última en particular, se hace cada vez más evidente a todos que "los medios mienten", que todo deviene juego de interpretaciones no desinteresadas». Cfr., VATTIMO, Gianni: Adiós a la verdad, traducción de D’MEZA, María Teresa. Gedisa, Barcelona, 2010. p. 9. 
GONZÁLEZ LAGIER, Daniel: Quaestio facti. Ensayos sobre prueba, causalidad y acción. Fontamara, México D.F., 2013.

HAACK, Susan: Filosofía del derecho y de la prueba. Marcial Pons, Madrid, 2020.

NIEVA FENOLL, Jordi: La valoración de la prueba. Marcial Pons, Madrid, 2010.

PICÓ I JUNOY, Joan (Director), ANDINO LÓPEZ, Juan y CERRATO GURI, Elisabet (Coordinadores): La prueba pericial a examen. Propuestas de lege ferenda. Bosch, Barcelona, 2020.

PICÓ I JUNOY, Joan (Director) y DE MIRANDA VÁZQUEZ, Carlos (Coordinador): Peritaje y prueba judicial. Bosch, Barcelona, 2017.

SCHAUER, Frederick: Pensar como un abogado. Marcial Pons, Madrid, 2013.

SOBA BRACESCO, Ignacio M.: Estudios sobre la prueba testimonial y pericial. La Ley Uruguay, Montevideo, 2020.

STEIN, Friedrich: El conocimiento privado del juez, segunda edición, traducción y notas DE LA OLIVA SANTOS, Andrés. Temis, Bogotá, $1893 / 1999$.

TARUFFO, Michele: La prueba. Marcial Pons, Madrid, 2008.

VATTIMO, Gianni: Adiós a la verdad, traducción de D’MEZA, María Teresa. Gedisa, Barcelona, 2010.

VÁZQUEZ, Carmen: De la prueba científica a la prueba pericial. Marcial Pons, Madrid, 2015 